\title{
A Comparative Study on the Generic Structure of Undergraduate Thesis Abstracts Between Native Speakers and Non-native Speakers in English Linguistics*
}

\author{
ZHENG Yan \\ Lanzhou Jiaotong University, Lanzhou, China
}

\begin{abstract}
This paper launches a comparative study on the generic structure of undergraduate thesis abstracts between native speakers and non-native speakers in English linguistics. The author, after adopting various means for collection and selection of 15 linguistic B.A. thesis English abstracts written by non-native speakers and 15 other linguistic B.A. thesis English abstracts written by native speakers, sets up two data-Non-native Speaker (NNS) and Native Speaker (NS), then analyzes and presents the compulsory and optional moves and steps that both NNS and NS follow with a focus on detailed analysis of compulsory moves and steps by using John Swales' CARS Model, and finally concludes the similarities and differences on the generic structure of B.A. thesis English abstracts between NNS and NS. Meanwhile, a pattern for generic structure of English B.A. thesis abstracts in Linguistics is offered to non-native students for reference. The present research therefore has considerable significance on the reading and writing of B.A. thesis English abstracts in Linguistics and it is conducive to relative teaching and further academic studies.
\end{abstract}

Keywords: genre analysis, B.A. thesis, English abstracts, comparative study

\section{Introduction}

In recent years, many applied linguists and linguistic researchers have become increasingly interested in the studies on the concept of genre and its application to researches in academic writing. Genre, after being introduced into linguistic field by ethnographers in the early 1980s, has drawn wide attention from the researchers, which later triggered many studies on genre analysis.

However, while the academic fruits about genre analysis are flourishing on research papers and conference papers in various fields and multiple disciplines, not so many researchers carry out relative studies on undergraduate thesis. The researches on undergraduate thesis abstracts prove to be even fewer. Meanwhile, "Abstracts continue to remain a neglected field among discourse analysts. This is unfortunate as they are texts particularly suited to genre investigation" (Swales, 1990, p. 181). Therefore, the topic discussed in this paper is worth exploration.

\footnotetext{
* Acknowledgements: This paper is the research of the key project of the Twelfth Five-Year Plan of Gansu Province Education and Science (Grant No. GS[2013]GHBZ088).

ZHENG Yan, associate professor, master, School of Foreign Languages, Lanzhou Jiaotong University.
} 


\section{Methodology}

Two equal-sized sets of data of English thesis abstracts in linguistics have been established: the data of B.A. thesis abstracts in linguistics by native English speakers and the data of English B.A. thesis abstracts in linguistics by non-native speakers.

The 15 abstracts of B.A. theses in the NS were collected from the website called Cardinal Scholar ${ }^{1}$ and downloaded from several official homepages of foreign universities for the present study. The 15 abstracts of B.A. theses in the NNS were selected from the English Department of Shandong University, Shanghai Normal University, Dalian University of Foreign Languages, Nanjing University of Technology, etc. All of the theses in the two sets of data were accomplished after the year of 2000.

According to YANG and Allison (2003), Swales' Move-Step analysis is considered as a robust method of genre analysis applied to analyze the generic structure of thesis abstracts under study. The author, therefore, employs Swales' (1990) CARS (Creating A Research Space) Model in the present study to analyze the generic structure of thesis abstracts in the two sets of data. The data are analyzed quantitatively and qualitatively and the results are analyzed statistically.

\section{Results and Discussions}

\section{Genre Studies on the Structure of Thesis Abstracts in NNS}

The author concludes that most non-native speakers compose undergraduate thesis by following the following move-step model:

Move 1: Establishing a territory

Step 1: Claiming centrality and/or

Step 2: Making topic generalization(s)

Move 2: Indicating a gap

Move 3: Outlining purpose(s)

Move 4: Announcing present research

Move 5: Making a summary

Step 1: Research significance

\section{Genre Studies on the Structure of Thesis Abstracts in NS}

Native speakers compose undergraduate thesis by following the following move-step model:

Move 1: Establishing a territory

Step 1: Claiming centrality and/or

Move 2: Indicating a gap

Move 3: Proposing methods

Move 4: Making a summary

Step 1: Research significance

\section{Comparison of Generic Structures of Thesis Abstracts Between NNS and NS}

From the findings of Move-Step analysis of abstracts in NNS and NS, we find that abstracts written by non-native speakers share some common features in the generic structure with those written by native speakers.

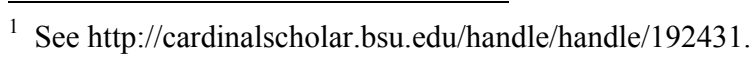


Here are some similarities that have been found:

(1) Both of them follow John Swales' CRAS model in general;

(2) Both have Establishing a territory, Indicating a gap, and Making a summary as their obligatory moves;

(3) For both of them, in move-Establishing a territory, step-Claiming centrality serves as an obligatory step; in move—Making a summary, step — Research significance serves as an obligatory step;

(4) For both of them, in move-Establishing a territory, step-Reviewing items of previous research serves as an optional step; in move—Making a summary, step—Major findings and step—Conclusions are two optional steps;

(5) Move cycles occur in abstracts of both data, and the move may occur in different order. Also, one same move or step may occur more than once in one abstract.

Here are differences we have found:

(1) For abstracts in NNS, Making topic generalization(s) is an obligatory step to realize the move-Establishing a territory while it is an optional step for abstracts in NS;

(2) For abstracts in NNS, Outlining purposes and Announcing present research are obligatory moves while they are optional moves for abstracts in NS;

(3) Proposing methods is an optional move for abstracts in NNS but a compulsory move for abstracts in NS;

(4) Thesis structure occurs in abstracts in NNS; however, it never occurs in abstracts in NS;

(5) In NS, 33.33\% native speakers use Introduction as an optional move; however, it never occurs in NNS;

(6) In NS, 6.67\% native speakers take Topic-analysing as an optional move but it never occurs in NNS;

(7) In NS, $13.33 \%$ native speakers use Limitation as an optional move but none of non-native speakers use it when writing an abstract;

(8) As for the length of abstracts, most abstracts in NS are shorter than those in NNS.

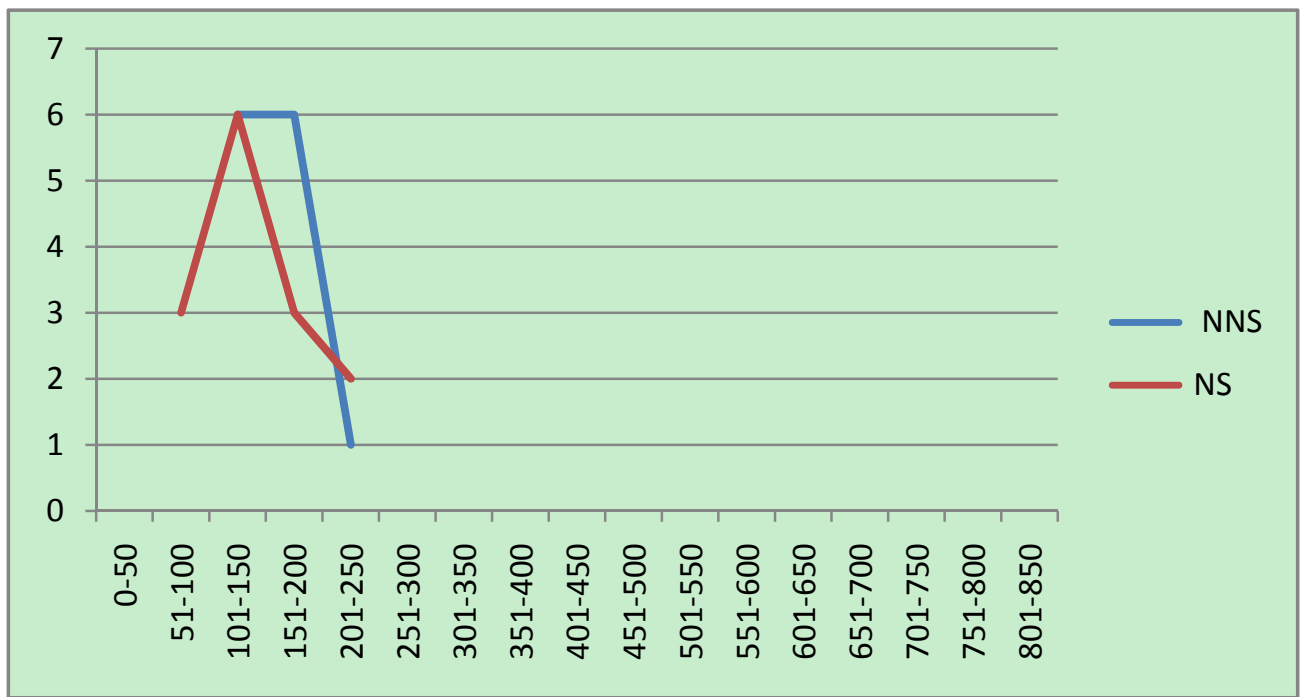

Figure 1. Difference in abstract length between natives and non-natives. 


\section{Conclusion}

The present research makes a tentative attempt to provide a common pattern for the generic structure of English undergraduate thesis abstracts in the field of English linguistics for reference.

Move 1: Establishing a territory

Step 1: Claiming centrality and/or

Step 2: Making topic generalization(s) and/or

Move 2: Indicating a gap

Move 3: Proposing Methods and/or

Outlining purposes and/or

Announcing present research

Move 4: Making a summary

Step 1: Research significance and/or

The present research could facilitate the reading, understanding, and writing of undergraduate thesis abstracts for non-native speakers in the field of English linguistics, so that undergraduate students can read and write thesis abstracts efficiently. Meanwhile, it is helpful for undergraduate thesis supervisors to guide students to write thesis abstracts smoothly.

Future studies may be carried out in a larger size of participants to confirm the findings, good command of corresponding subjects, suggestions from experts, and several times' check are extremely necessary and important during the process of identification of moves and steps.

\section{References}

Allison, D., \& Tauroza, S. (1995). The effects of discourse organization on lecture comprehension. English for Specific Purpose, 14(2), 157-173.

Bhatia, V. K. (1993). Analyzing genre: Language use in professional settings. London \& NY: Longman.

Brett, P. A. (1994). Genre analysis of the results section of sociology articles. English for Specific Purpose, 13(1), 47-59.

Holmes, R. (1997). Genre analysis and the social sciences: An investigation of the structure of research article discussion sections in three disciplines. English for Specific Purpose, 16(1), 321-337.

Swales, J. M. (1990). Genre analysis: English in academic and research settings. Shanghai: Shanghai Foreign Language Education Press.

YANG, R. (2001). A genre analysis of research articles in applied linguistics (Unpublished Ph.D. thesis, National University of Singapore, Singapore).

YANG, R. Y. (2006). 体裁分析的应用: 应用语言学学术文章结构分析 (The application of genre analysis: Genre analysis on academic paper in applied linguistics). 外语与外语教学, 10, 29-34.

YANG, R. Y., \& Allison, D. (2003). Research articles in applied linguistics: Moving from results to conclusions. English for Specific Purpose, 22, 365-385.

YANG, R. Y., \& Allison, D. (2004). Research articles in applied linguistics: Structures from a functional perspective. English for Specific Purpose, 23, 264-279. 